\title{
DIREITA, ESQUERDA E OS CORRETOS NA LITERATURA INFANTIL
}

\section{RIGHT, LEFT AND THE CORRECTNESS IN CHILDREN'S LITERATURE}

\author{
https://doi.org/10.20873/uft2179-3948.2020v11n3p39-56
}

Vita Ichilevici $^{1}$

\begin{abstract}
Resumo
$\mathrm{O}$ artigo trata de um novo tipo de censura que atinge obras de literatura infantil a partir de demandas ideológicas e tensões entre grupos progressistas e conservadores, cada qual com seu rol de temas e termos corretos. Sem fundamentos teóricos, tal censura se baseia em discursos indignados, que se iniciam, quase sempre, nas redes sociais. A partir da análise de dois casos recentes de retirada de circulação de livros infantis - um provocado por argumentos tidos como de esquerda, o outro, de direita - nosso objetivo é analisar os efeitos das tentativas de restrição sobre o acesso da criança a determinadas obras.
\end{abstract}

Palavras-chave: literatura infantil; ideologia; censura; mediação.

\begin{abstract}
The article examines a new kind of censorship of children's books, triggered by ideological demands and tensions between progressive and conservative groups, each with their own agenda of correct themes and terms. Lacking any theoretical base, such censorship begins with indignant speeches, usually started on social networks. Through the analysis of two recent cases of withdrawal of children's books from circulation - one caused by claims considered to be on the left, the other on the right -we aim to analyze the effects of such attempts to restrict children's access to certain literary works.
\end{abstract}

Keywords: children's literature; ideology; censorship; mediation.

\footnotetext{
${ }^{1}$ Doutoranda do Programa de pós-graduação da Faculdade de Educação da USP, tem como grande área de pesquisa a Literatura Infantil e seu uso na escola - vita.ichilevici@usp.br
} 
censura deixa de atuar, sob a sua forma mais perversa e ativa, a das pautas.

(SUDATTI, SELIGMANN-SILVA, 2018, p.66)

O que autores como Milton e Heine, censura de Estado e pautas têm a ver com os corretos ${ }^{2}$ e censuras na literatura infantil e juvenil (LIJ)? Tudo - desde que se adote como premissas (i) o entendimento da leitura como prática social e (ii) que a literatura infantil, que já nasce associada a objetivos pedagógicos, tem sido usada, desde sempre, como instrumento para transmissão de valores.

A LIJ não está encerrada em uma bolha à prova das questões que mobilizam a sociedade. Pelo contrário, é fortemente impactada por elas, já que, como reza a sabedoria popular, é de pequenino que se torce o pepino.

Pensemos, inicialmente, o que é LIJ? Não sendo possível, no espaço deste artigo, discutir quais seriam os limites que circunscrevem a LIJ - ou, mesmo, se é possível estabelecê-los tomemos, dentre as diversas abordagens teóricas, nem sempre coincidentes, a sugerida por Perry Nodelman $^{3}$ (2008): são livros publicados tendo a criança como público-alvo ou, mais precisamente, é a ideia que adultos têm da criança em determinado período histórico. Livros que oferecem à criança aquilo que os adultos acreditam que ela vá gostar e o que gostariam que ela precisasseem outras palavras, aquilo que satisfaz as necessidades do adulto em relação à criança.

Para tratar da censura na LIJ, presente desde sempre em obras dirigidas à criança, é preciso retroceder alguns passos para, de saída, buscar definiçõos que permitam estabelecer uma base comum para o que será tratado a seguir.

A perspectiva aqui adotada vai no sentido de compreender a censura a partir de sua motivação, ou seja, da intenção prévia de proibir aquilo que não se julga adequado, aceito, permitido. Em tempos recentes, a expressão politicamente correto (PC) tem sido utilizada- por aqueles que se opõem a esta prática - como sinônimo de censura. Fortemente associada à ideologia, a discussão sobre o PC vem marcando presença na imprensa, redes sociais, e - o mais grave - em pronunciamentos oficiais no Brasil, e países mundo afora governados por (ou com forte presença de) partidos populistas de direita ou extrema direita. Conceito ambíguo e amorfo, campo de

\footnotetext{
${ }^{2}$ Destaque para o plural - o julgamento do que é correto está longe de ser universal.

${ }^{3}$ Todas as traduções de referências em língua estrangeira são da autora deste artigo.
} 
disputas e embates (ao invés de debates), PC pode ser entendido, de acordo com o Cambridge Dictionary, como o cuidado de evitar uso de linguagem ou comportamento que possa ser considerado grosseiro ou ofensivo por determinados grupos sociais. Definição que não chega a ser suficiente, tal o uso indiscriminado da expressão politicamente correto em anos recentes. Tão amplo é seu alcance que, no final de 2017, foi tema de toda uma edição da Revista USP, que inclui, entre as perguntas iniciais ${ }^{4}$ que propõe: o politicamente correto provém, afinal, da esquerda ou da direita? Questão igualmente relevante para tentar compreender as motivações para as demandas de censura na LIJ.

Ainda que não seja necessário - ou mesmo possível - no âmbito deste artigo, discutir em profundidade as origens históricas do PC, é preciso indicar que teve início nos campi das universidades norte-americanas nos anos 1970, tendo como pano de fundo a recém-chegada diversidade cultural. bell hooks 5 (2013) ajuda a colocar em perspectiva o fenômeno, que dividia e provocava desconforto em docentes e alunos, ao indicar que alguns pareciam acreditar que as novas exigências queriam "substituir uma ditadura do conhecimento por outra, (...) [o que não corresponde] com precisão as visões progressistas de como o compromisso com a diversidade cultural pode transformar construtivamente a academia (p. 49)". A partir daí, articulou-se definitivamente no contexto das chamadas guerras culturais dos anos 1980 e 1990, alastrando-se com relativa rapidez para outros espaços sociais e países.

Apesar de ser bastante comum que as demandas sociais de controle de linguagem sejam todas colocadas no mesmo balaio do politicamente correto, é fundamental delimitar do que exatamente se trata. Nos anos 1990, John Wilson (1995) já indicava que o PC havia sido apropriado pelos conservadores e utilizada para atingir inimigos de seu campo político, reunidos em uma única conspiração da qual faziam parte defensores do feminismo, multiculturalismo, ações afirmativas e lutas por direitos sociais amplos. E Ruth Perry (1992), na mesma época lançava o alerta: apesar de os críticos do PC esgrimirem como argumento sua suposta isenção e neutralidade, nada poderia estar mais distante da realidade.

\footnotetext{
${ }^{4}$ A esse respeito, pode-se destacar "as correlações entre seu sentido afirmativo ou negativo e a clássica dicotomia esquerda/direita" e "o abuso [de um conceito historicamente identificado com a esquerda que] serve de munição às posições de direita" (DOSSIÊ POLITICAMENTE CORRETO, 2017, p. 9/30)

${ }^{5}$ O pseudônimo bell hooks, adotado por Gloria Jean Watkins, é grafado em minúsculas por decisão da autora, para "chamar atenção para sua mensagem, não para si" (RODRIGUEZ, 2019).
} 
Décadas depois, Weigel (2018) argumenta que o que de fato existe são campanhas contra o que se convencionou chamar de politicamente correto, e que este até o final dos anos 1980

era usado exclusivamente no campo da esquerda, e quase sempre com ironia, como uma crítica ao excesso de ortodoxia. (...) Mas logo a expressão seria redefinida pela direita, que virou do avesso seu significado. (...) [transformando-o em] tema de discursos neoconservadores. Eles diziam que o PC constituía um programa político da esquerda que estava assumindo o controle das universidades e instituições culturais norte-americanas. E eles estavam decididos a acabar com isso (n.p.)

As principais áreas de disputa relativas ao PC são questões de raça, gênero e orientação sexual. Já aquelas do espectro do conservadoramente correto, que adoto a partir do termo cunhado por Wilson (1995), dizem respeito a sexo e, de maneira geral, a assuntos ligados ao corpo e, em menor escala, àqueles de cunho religioso ${ }^{6}$. Assuntos como paz, sustentabilidade, respeito à natureza e aos animais, também caros ao politicamente correto, não costumam provocar debates e embates. Já temas como diversidade, igualdade racial, estereótipos, identidade de gênero ${ }^{7}$ e modelos não normativos de família são pretextos de discórdias, polêmicas acaloradas e controvérsias.

Nesse contexto, brevemente exposto, encontram-se também as polêmicas relacionadas à literatura infantil. Assim, a discussão sobre as interdições e proibições impostas à LIJ que aqui se propõe, pode ser, genericamente, formulada através de algumas perguntas: (i) trata-se de cuidado ou censura? (ii) de que forma as demandas do politicamente e aquelas do conservadoramente correto manifestam-se na LIJ?; (iii) que caminhos podemos buscar para lidar com elas?

A censura, como nos lembra a epígrafe no início do texto, é tema antigo. Sua definição, de acordo com o dicionário Houaiss ${ }^{8}$ (2012), é: "exame a que são submetidos trabalhos de cunho artístico ou informativo, ger. com base em critérios de caráter moral ou político, para decidir sobre a conveniência de serem ou não liberados para apresentação ou exibição ao público em geral". Função habitualmente exercida por quem detém o poder legal, religioso ou institucional. Controle este em nada semelhante àquele que o próprio escritor, ainda que muitas vezes de forma

\footnotetext{
${ }^{6}$ Como exemplo, tome-se a recente denúncia, amplamente noticiada, da atual ministra da Mulher, da Família e dos Direitos Humanos, Damares Alves, da existência nas escolas de "um manual de bruxaria para crianças". O vídeo (de 2016, antes, portanto, da posse da ministra) tornou-se amplamente conhecido em maio de $201^{9}$, e refere-se ao livro, Manual Prático de Bruxaria em Onze Lições (Malcolm Bird, Editora Ática, 2000), que traz lições bem-humoradas sobre a vida das bruxas modernas. A sátira, é claro, foi ignorada na denúncia.

${ }^{7}$ Que não guarda relação com ideologia de gênero, conceito difundido pela extrema direita como movimento que supostamente visaria depreciar a família tradicional, não reconhecido, porém, pela comunidade acadêmica.

${ }^{8}$ Grande Dicionário Houaiss (online).
} 
inconsciente, exerce em sua obra - na escolha da melhor palavra ou do percurso narrativo mais adequado. Ou à do crítico especializado que, ao fazer sua apreciação, considera certas particularidades de uma obra. Ou, ainda, à determinação dos editores de evitar temas potencialmente polêmicos - uma vez que, no caso da LIJ, há livros que poderão vir a participar de editais públicos, resultando em expressivo volume de vendas e importantíssima fonte de receita para as editoras. Os critérios utilizados pelos censores oficiais, investidos de poder e autoridade, nada têm a ver com a qualidade da obra, mas, sim, com a busca de indícios e sinais que justifiquem - aos olhos do regime ou instituição que representam - a proibição. E aqui, vale um alerta: a censura fez parte de todos os regimes totalitários, antigos e atuais, "mas nossas ditas democracias tampouco são inocentes. Clássicos e obras de literatura contemporânea foram retirados das estantes e das bibliotecas públicas ou escolares em nome de um 'politicamente correto' tão pueril quanto degradante" (STEINER, 2017, p. 31).

Veremos, mais à frente, que há também censuras - no sentido de controle moral - de outra natureza que não as aqui classificadas como oficiais. Mas, antes, passemos a dois recentes casos brasileiros ${ }^{9}$ de retirada de circulação de livros infantis. A escolha não é casual - além de ambos terem tido grande repercussão na grande imprensa, revistas especializadas e redes sociais, foram provocados, um por alegações de desrespeito a valores identificados como progressistas (ou seja, da esfera do PC), o outro por demandas do campo conservador.

O primeiro é Peppa (Silvana Rando, Brinque Book, 2009), livro que, em 2010, fez parte de compras da Prefeitura de São Paulo para acervo de bibliotecas de escolas de Educação Infantil. Eleito, no mesmo ano, um dos três melhores livros do ano pela revista Crescer, com 27.000 exemplares vendidos, estava na décima reimpressão em 2017.

A personagem Peppa, uma linda menina com o cabelo mais forte do universo "adorava dias de ventania, dias de feira, brincar de cabo-de-guerra, e dias de mudança. Mas detestava quando sua mãe cortava um fio de seu cabelo para fechar o pacote de biscoitos!" Peppa cresce feliz, e seu cabelo cresce com ela até que um dia ... ao ver um cartaz na frente de um salão de beleza, e após passar a noite toda pensando, decide alisar os cabelos. Junto com o cabelo liso, que Peppa consegue depois de um longo, muito longo processo, vem "a parte chata da história: uma enorme lista de

\footnotetext{
${ }^{9}$ A precisão se faz necessária uma vez que há numerosos casos também em outros países.
} 
proibições!" Peppa não pode mais nadar na piscina, rolar na grama, tomar chuva, transpirar, pular, correr ou rir demais... e muitas outras coisas, que deixam sua vida muito, muito chata. Até que em um dia de "calor que começava lá no dedão dos pés e subia até as orelhas. Insuportável!" Peppa, muito irritada, não aguenta mais aquela vida tão certinha e sem graça, pula na piscina e volta a ser a menina feliz de cabelos cacheados e indomáveis.

Se as dificuldades da personagem começam quando ela decide ir contra sua natureza, as do livro tiveram início a partir de uma denúncia publicada em um canal no YouTube em abril de 2016. No vídeo, Ana Paula Xongani ${ }^{10}$ relata ter conhecido o livro na creche da filha, para, em seguida, afirmar que "todas as páginas do livro têm um problema, é um livro extremamente racista". A análise, página a página, é concluída pela autora, afirmando que "estamos cerceando a liberdade das crianças de brincar com sua beleza natural", e" [preocupa o fato de] o livro está sendo veiculado nas escolas e muito mais em saber que a autora ganhou prêmios como um dos melhores livros".

Não é sem importância o fato de Peppa ser uma menina branca de cabelos cacheados - a relação negativa que Xongani estabelece com o cabelo crespo do negro não existe no texto ou nas ilustrações. Pelo contrário, as imagens de Peppa nas diferentes cenas em que seu cabelo é usado de maneiras não convencionais mostram-na sempre sorrindo e feliz, a não ser quando a mãe usa um fio de seu cabelo para fechar o pacote de biscoito.

Em outubro de 2017, o vídeo ganhou repercussão ao ser republicado pelo professor de história Carlos Machado em sua página no Facebook, e a polêmica em torno de Peppa invadiu os principais jornais do país. Em nota publicada também no Facebook (e em seguida apagada ${ }^{11}$ ), a reação inicial da escritora Silvana Rando foi afirmar que Xongani fez uma leitura equivocada de seu livro, que

fala da vaidade exagerada na infância, de trocar a liberdade de ser criança pelos padrões de beleza. (...) Você já sofreu por não estar dentro de 'padrões'? Eu já. E que droga de padrão é esse? (...) Gostar de como somos é tão maravilhoso que quis deixar isso num

\footnotetext{
${ }^{10}$ Que se apresenta como "formada em design, é sócia-fundadora e estilista da Xongani. Atua também como youtuber (...) [tratando de] moda e estilo afro-brasileiro, moda e militância, beleza negra, feminismo negro, empoderamento e autoestima da mulher negra e desafios do empreendedorismo negro no Brasil". Disponível em https://xongani.com/elements/pages/about/, acesso em 10. set. 2019.

${ }^{11}$ No universo digital, porém, como todos sabemos, toda informação é guardada e retorna para nos assombrar. Quando Rando apagou sua publicação inicial, cópias já estavam circulando no ecossistema virtual, inclusive em vídeos de Ana Paula Xongani que se seguiram ao primeiro.
} 
livro para as crianças (...). Em momento algum quis ofender, ou comparar o cabelo da personagem aos cabelos cacheados, que considero de tamanha beleza.

No meio literário, a defesa de Peppa foi unânime. Jornais de grande circulação também se posicionaram contra a acusação de racismo, denunciando pedidos de remoção de livros infantis de escolas, sempre com argumentos que, supostamente, visam resguardar as crianças. Argumentos estes que tanto podem ser progressistas quanto conservadores. Veículos especializados em literatura infantil e educação, como as revistas Emília e Carta Educação, procuraram trazer à luz os dois lados da questão - mas a discussão girou em torno dos efeitos nocivos de livros de conteúdo racista - o que, evidentemente, não está em discussão - sem contrapor as críticas de Xongani ao texto e ilustrações do livro. ${ }^{12}$

Alguns dias após a publicação inicial, Rando voltou ao Facebook para dizer: "depois de ler e reler a opinião de todos a respeito do meu livro Peppa, gostaria de afirmar que se existe a chance de uma única criança se ofender com seu conteúdo, prefiro que o livro deixe de existir, pois só assim meu trabalho fará sentido". A pedido da autora, a editora recolheu todos os exemplares ainda à venda, mas, até onde se sabe, não aqueles distribuídos a EMEIs da cidade de São Paulo.

Em um segundo vídeo sobre Peppa, Xongani relata seu périplo junto à Secretaria Municipal de Educação de São Paulo para discutir o caso, e indica dois livros que entende poderem ajudar "na construção da autoestima e da beleza dessa criança negra". O terceiro vídeo foi publicado cerca de seis meses depois, em um "dia de comemoração", após a informação de que o livro seria recolhido pela editora.

Não é possível afirmar se outras razões, além da alegada por Silvana Rando (e repetida em entrevistas posteriores) motivaram a decisão de retirada do livro, mas é preciso registrar a intensa campanha de agressão e difamação que sofreu, nas redes sociais e em comentários no canal de YouTube em que o vídeo foi originalmente publicado. Também Ana Paula Xongani foi alvo de severas críticas, especialmente - mas não apenas - por parte de escritores, ilustradores e editores

\footnotetext{
${ }^{12}$ Não foi possível encontrar menção às inconsistências, apontadas nessa breve análise das críticas feitas a Peppa no vídeo de Ana Paula Xongani, em nenhuma das fontes consultadas: comentários em redes sociais, artigos de jornais de grande circulação ou, mesmo, em revistas (Emília, Carta Educação) e debates (CBN) de especialistas.
} 
de livros infantis. Os especialistas questionaram sua autoridade ${ }^{13} \mathrm{em}$ criticar uma obra de literatura infantil, já vários dos seguidores de seu canal criticaram a leitura - a seu ver, enviesada - do livro.

Entre os comentários na trilogia de vídeos sobre Peppa, há muitas pessoas que concordam com a análise de Xongani. Seus comentários são, em geral, curtos e enfáticos. Já entre os que divergem dela, há aqueles que apenas manifestam sua discordância, os que são agressivos e ofensivos, e - em menor número - comentários mais longos que procuram argumentar com a interpretação de Xongani.

O imbróglio está no fato de que os comentários, quando confrontados com a obra, não correspondem à realidade. Por exemplo, a afirmação de que a autora foi premiada por Peppa. Em 2011, Silvana Rando recebeu, de fato, o prêmio Jabuti de melhor ilustração de livro infantil ou juvenil, mas não por Peppa, e sim por Gildo (Brinque Book, 2010), a história de um elefante, ao mesmo tempo, corajoso e medroso. Outras alegações seguem na mesma linha dos fatos alternativos $^{14}$, até chegar ao que Xongani considera o ápice do absurdo, a última frase do livro: "e lá se foi o cabelão sedoso e liso de Peppa". Fica difícil enxergar o problema ao confrontar as ilustrações em que Peppa aparece feliz ao recuperar o cabelo que é sua identidade e marca registrada, e aquelas em que fica evidente o desconforto com o cabelo liso. O cerceamento à beleza natural que Xongani enxergou no livro é como um espelho mágico que distorce o que dizem texto e imagem - Peppa fica impedida de brincar apenas quando não se aceita do jeito que é.

O segundo caso, situado no lado oposto do espectro político, é A triste história de Eredegalda, um dos contos de Enquanto o sono não vem (José Mauro Brant, Editora Rocco, 2003). O livro, selecionado em 2014 pelo CEALE ${ }^{15}$ como parte do acervo do PNAIC $^{12}$ e distribuído a

\footnotetext{
${ }^{13}$ No último dos três vídeos, publicado em novembro de 2017, a autora da denúncia comemora a retirada do livro do mercado e responde às críticas dizendo que "definitivamente eu não sou uma profissional da literatura, nem pretendo ser. (...) faço da moda minha plataforma de transformação social. Eu falei do livro do meu lugar de fala (...) de uma mãe preocupada na educação da sua filha". Em julho de 2020, a Companhia das Letras, dentro de seu projeto de diversidade, anunciou a contratação de Ana Paula Xongani como editora convidada de conteúdo do selo Paralela, que integra o grupo editorial.

${ }^{14}$ Termo que ficou célebre após ser utilizado, em 2017, por uma Conselheira do Presidente dos Estados Unidos em entrevista à rede NBC.

${ }^{15}$ CEALE - Centro de Alfabetização, Leitura e Escrita da Faculdade de Educação da Universidade Federal de Minas Gerais, um dos mais renomados do país na área de alfabetização e letramento. / PNAIC - Programa Nacional de Alfabetização na Idade Certa.
} 
escolas públicas de todo o Brasil, teve o recolhimento de 93.000 exemplares determinado pelo MEC em 2017, a partir de denúncias do que certos grupos entenderam como incentivo ao incesto.

Baseado em um conto de tradição oral recolhido pelo autor em Barbacena, Minas Gerais, o enredo de Eredegalda segue a estrutura narrativa do conhecido Pele de Asno, de Charles Perrault, e tem como tema central a história de um rei que quer casar-se com a própria filha. Os finais, no entanto, são diferentes - Pele de Asno, depois de fugir para escapar do pai, recebe sua bênção para o casamento com um lindo príncipe; já Eredegalda, trancafiada na torre por rejeitar o desejo do rei, morre de sede antes da chegada dos três cavalheiros que o pai, arrependido, manda para socorrêla. O final trágico posiciona o conto na categoria de mitos, gênero em que

encontramos quase todos os tipos de ligações incestuosas que também surgem nos contos de fadas. Mas nos contos, a estória do herói mostra como estas relações infantis potencialmente destrutivas podem ser, e são, integradas no processo de desenvolvimento. No mito, as dificuldades edípicas vêm à tona e por isto tudo termina numa destruição total, sejam as relações positivas ou negativas (BETTELHEIM, 2002, p.212).

A ausência do final feliz ou os aspectos psicanalíticos citados por Bettelheim, que possibilitam à criança vivenciar através de uma situação ficcional sentimentos que nem sequer saberia explicar, foram irrelevantes para a interdição. A razão para o banimento do livro não é a morte trágica da protagonista, e, sim, o suposto - e inexistente - incesto.

Para a Secretaria de Educação Básica (SEB), "as crianças no ciclo de alfabetização, por serem leitores em formação e com vivências limitadas, ainda não adquiriram autonomia, maturidade e senso crítico para problematizar determinados temas com alta densidade, como é o caso da história em questão". Argumentos incontestáveis, mas que não consideram a - não só possível, mas necessária - contextualização da história pelo mediador adulto, que deveria conduzir a criança pelos caminhos da leitura, contribuindo com comentários e informações que mantenham a história no plano simbólico, exercendo um papel de guia ou capitão, como propõe Beatriz Robledo (2017).

Ao desprezar o universo simbólico, a linguagem poética, as ilustrações do mundo do faz de conta - princesa, torre - familiar às crianças, torna-se impossível perceber como o conto expõe o sofrimento de possíveis vítimas da ação abusiva de adultos e, ao mesmo tempo, condena o incesto. Bloqueia-se a possibilidade de elaboração de certos conteúdos, através da qual "às vezes o leitor encontra a energia, a força para sair de um contexto em que estava preso" (PETIT, 2013, p. 46). É o que faz o parecer técnico da SEB ao posicionar uma narrativa de ficção na mesma chave do texto 
informativo. Essencial na tarefa de ajudar a criança a ordenar e se situar em um universo de múltiplas informações, o texto informativo tem recepção distinta do literário, diferença da qual o mediador adulto deve ter clareza e considerar ao fazer a leitura com a criança.

As interdições a Peppa e Eredegalda, motivadas por razões culturais muito distantes, guardam mais semelhanças do que pode parecer à primeira vista. Em primeiro lugar, a censura aos dois livros não foi imposta pelo Estado - ainda que, em um dos casos, o recolhimento tenha sido ordenado por um órgão oficial. Além disso, ambos foram adotados para uso na escola, ou seja, potencialmente chegariam a muitas crianças. Esse é um importante fator a ser considerado, uma vez que a aproximação da criança com a leitura no Brasil - e na América Latina como um todo se dá prioritariamente pela via da escola.

O que levou a denúncias e exigência de remoção dos dois livros foram interpretações morais partilhadas apenas por uma parcela da sociedade, não as revoluções morais de que trata o filósofo e crítico cultural K. A. Appiah (2012). A partir de exemplos históricos, o autor defende a ideia de que mudanças sociais somente são possíveis quando o contingente daqueles que se opõem a determinadas práticas supera o número dos que as aprovam. Por exemplo, ainda que os argumentos contra a escravidão fossem, há muito, conhecidos, para Appiah a abolição aconteceu quando grande parcela da sociedade passou a considerar a prática moralmente intolerável.

Não é o caso de Peppa e Eredegalda, abatidas por certos valores ${ }^{16}$, construídos a partir de preconceitos sustentados por crenças pessoais. Valores opostos, mas igualmente alinhados à percepção da criança pelas contraditórias lentes de autonomia e proteção - se, por um lado, nada mais parece ser proibido na era da hiperconexão acessível a todos, por outro, proliferam tendências moralizantes e infantilizadoras. O que está por trás das denúncias - racismo em Peppa, incesto em Eredegalda - são interpretações particulares, motivadas por razões de que somente podemos suspeitar.

Todo texto implica um sujeito [o autor] que lhe dá forma, e um sujeito é também uma posição (...). Ler é também reencontrar este projeto de dizer. (p.31). Nossas leituras

\footnotetext{
16 "Atribuem-se ao valor dois caracteres contrastantes, o absoluto e o relativo: o primeiro constitui o modo de ser do valor em si e o segundo, o seu modo de ser na história. A história é aqui entendida como relativa, (...) posição de Max Weber (1864-1920) que via na história uma incessante criação de valores, cada qual relativo ao fugaz momento em permanente luta com valores diferentes que se oferecem ao arbítrio do homem. Este mesmo reconhecimento da pluralidade de valores encontra-se no filósofo norte-americano John Dewey (1859-1952), que definiu a filosofia como a crítica dos valores" (GOERGEN, 2005, p. 989).
} 
também são situadas e datadas e na maioria dos casos responde a um projeto de escuta, não desinteressado (GERALDI, 2013, p.35).

Discordar da acusação de racismo a Peppa nada tem a ver com o reconhecimento da existência do racismo estrutural, chaga que segue aberta em nossa sociedade. Da mesma forma, divergir do banimento de Eredegalda não equivale à convicção de que determinadas obras de arte são inadequadas, ou simplesmente incompreensíveis, para certas faixas ${ }^{17}$ etárias. Em ambos os casos, o adulto, ao enxergar no(s) texto(s) aquilo que lhe aflige, achou por bem estender seu malestar à criança, evitando tratar de temas que causam angústia a ele, adulto.

Como já mencionado, os principais temas que sofrem tentativas de controle por parte de grupos conservadores são aqueles relacionados à sexualidade e, de maneira geral, ao corpo; do lado do politicamente correto as áreas de disputa são raça, gênero e orientação sexual. Estranhamente, apenas no segundo caso a liberdade de expressão costuma ser invocada para se questionar demandas de exclusão (ou adequação) de obras que desrespeitam grupos identitários.

A liberdade de expressão precisa ser compreendida para além do senso comum e do jargão que domina grande parte dos discursos a respeito do PC. A defesa da liberdade de expressão, assim como o PC, nos chega a partir dos Estados Unidos, país com forte preocupação com o direito individual em termos de liberdade de pensar e se expressar. Objeto da Primeira Emenda à Constituição dos EUA (1791), a liberdade de expressão tinha originalmente apenas caráter legal. A partir das décadas finais do século XX, no entanto, o tema chegou aos tribunais, onde algumas decisões judiciais ampliaram seu escopo, estendendo o direito de livre manifestação a outras formas de discursos (como, por exemplo, o político, o anônimo e o escolar). Já outras sentenças restringiram seu alcance, retirando do direito à liberdade de expressão tudo que pudesse ser caracterizado como discurso de ódio.

No Brasil, a legislação que mais se aproxima da ideia de liberdade de expressão, ainda que sem o mesmo valor simbólico da Primeira Emenda da Constituição dos Estados Unidos, são (i) o inciso IX do artigo $5^{\circ}$ da Constituição Federal (1988), que determina ser "livre a expressão ${ }^{18}$ da

\footnotetext{
${ }^{17}$ A indicação de faixa etária em livros infantis vem, progressivamente, sendo deixada de lado, substituída pelo conceito de "competência do leitor". Ainda assim, é inquestionável que nem todas as obras literárias são acessíveis a crianças.

${ }_{18}$ Tema subjacente à discussão do Projeto de Lei (PL 2.630/2020), que cria a Lei Brasileira de Liberdade, Responsabilidade e Transparência na Internet. Popularmente conhecida como Lei das Fake News, foi aprovada no Senado Federal em junho/2020 e encaminhado para apreciação à Câmara dos Deputados.
} 
atividade intelectual, artística, científica e de comunicação, independentemente de censura ou licença"; e (ii) o artigo $220, \S 2^{\circ}$, que estabelece ser "vedada toda e qualquer censura de natureza política, ideológica e artística".

Vale dizer que liberdade de expressão é um direito relativo, que convive com outros, e que tem seu sentido sequestrado quando ultrapassa o ponto de inflexão em que se torna um inaceitável discurso de ódio, usado para insultar e humilhar. Além disso, a liberdade de expressão passa a vigorar apenas a partir do que indivíduos ou grupos sociais tenham determinado como linguagem aceitável.

Como também já vimos, as interdições aos dois livros tomados como exemplo, à direita $\mathrm{e}$ à esquerda, dizem respeito à leitura do adulto - a criança sequer teve a possibilidade de ter acesso às histórias de Peppa e Eredegalda. Censura justificada por um suposto cuidado, que compromete de forma nociva a leitura mediada, já que o adulto projeta sua visão na leitura, como "uma escala de valores ausente (...) [trazendo mais pistas] sobre o ponto de vista do sujeito que lê do que sobre o texto" (JOUVE, 2012, p. 58, itálico meu).

Outras leituras seriam possíveis? Vejamos.

O parecer técnico da SEB, ao interpretar ipsis litteris o enredo do conto sobre o rei que queria tomar a filha como esposa, denota um horizonte literário restrito, desprezando o simbolismo característico dos contos tradicionais. Realiza uma leitura sem profundidade, que desconsidera aspectos que não estão na superfície do conto - o medo provocado pelo rei na rainha e nas outras filhas; a coragem e firmeza de Eredegalda, única que o desafia; o arrependimento do pai, que desiste do casamento e envia, ainda que tardiamente, três cavalheiros para socorrer a filha castigada.

No caso de Peppa, a denúncia de racismo é feita a partir de um lugar de fala claramente assumido pela acusadora. Aliás, lugar de fala, expressão que veio a se tornar uma espécie de jargão, surgiu nos anos 1970 a partir de uma perspectiva teórica feminista, que compreende o conhecimento como decorrente da posição social, e rejeita a ideia de objetividade da ciência tradicional. Incorporado por outros movimentos identitários significa, grosso modo, que as hierarquias sociais determinam diferentes verdades e que atores sociais devem falar por si mesmos. No entanto, quase meio século após seu surgimento, lugar de fala passou a ser usado também como 
ferramenta conceitual de cunho ideológico, de rápida assimilação e adesão, apropriada para mobilização e engajamento na luta política (GOMES, 2019).

Ana Paula Xongani parece buscar, em cada uma das páginas do livro, elementos que confirmem - ainda que de forma fantasiosa - o argumento que defende. É bastante singular tanto a leitura que faz do livro de Silvana Rando, quanto os que recomenda como alternativa ao racismo que enxerga em Peppa: $O$ cabelo de Lelê (Valéria Belém e Adriana Mendonça, Companhia Editora Nacional, 2012) e Chico Juba (Gustavo Gaivota e Rubem Filho, Mazza, 2011).

De forma bastante resumida, a personagem Lelê é uma menina negra, que não gosta e não entende de onde vêm seus cabelos cacheados. Até que descobre um livro sobre países africanos, que lhe dá a chance de compreender sua ancestralidade e se reconciliar com seus cabelos. Já o personagem Chico, também negro, tampouco gosta de seu cabelo, e vive inventando soluções engenhosas para modificá-lo. Todas as suas ideias dão errado, e apenas no final Chico assume com alegria sua juba e direciona - agora, sim, com sucesso - sua criatividade à moda.

O livro de Lelê merece a recomendação de Xongani por ser "extremamente colorido, e lúdico", qualidades claramente presentes também em Peppa. O de Chico é indicado porque ele "aceita seu cabelo". Falta dizer que isso acontece apenas depois de passar boa parte da narrativa tentando transformá-lo. Peppa, por sua vez, logo se arrepende do cabelo artificialmente liso, que mantém por um curto período.

Os três livros tratam da importância da autoaceitação da criança, têm bons textos e ilustrações. Como um deles foi banido a partir da leitura, no mínimo singular, e receios do adulto, parece importante verificar o que têm a dizer as crianças. $O$ cabelo de Lelê foi uma das obras adotadas por Silveira et al. (2012) no projeto Narrativas, diferenças e infância contemporânea ${ }^{19}$, que buscou avaliar a percepção que as crianças participantes tinham de representações de raça e gênero na LIJ. Os autores atestam a boa qualidade do livro, mas chamam atenção para algumas reações - o branqueamento de Lelê, que apareceu em vários dos desenhos que as crianças produziram após a leitura; perguntas como: "será que tem piolho nesse cabelo?", "por que ela não corta esse cabelo?"; e sugestões para que Lelê alisasse os cabelos ou fizesse trancinhas. Reações

\footnotetext{
${ }^{19}$ Desenvolvido ao longo de três anos por uma equipe interinstitucional dos Programas de Pós-Graduação em Educação da UFRGS (Universidade Federal do Rio Grande do Sul) e ULBRA (Universidade Luterana do Brasil) e da Faculdade de Educação da UFRGS.
} 
que revelam, além da apropriação de signos compartilhados nos espaços sociais em que vivem essas crianças, a imprevisibilidade da leitura de um livro cuidadosamente selecionado pelo adulto.

Após a apresentação dos casos de interdição - à direita, Eredegalda, à esquerda, Peppa - e antes das conclusões (possíveis, no espaço aqui disponível) sobre os diferentes corretos na LIJ, falta estabelecer a relação entre medo, censura e ideologia. Pois, ao fim e ao cabo, é a ideologia que está por trás do que aqui se pretendeu discutir - embargos de um lado e outro, em nome de valores progressistas ou conservadores.

Também ideologia está no rol dos termos largamente empregados no(s) discurso(s) social(is) sem o necessário cuidado - como, por exemplo, em ideologia partidária, falsidade ideológica, e no contemporâneo, ideologia de gênero. O dicionário Houaiss (2012) atribui à ideologia, entre outros, o sentido de "sistema de ideias (crenças, tradições, princípios e mitos) interdependentes, sustentadas por um grupo social de qualquer natureza ou dimensão, as quais refletem, racionalizam e defendem os próprios interesses e compromissos institucionais, sejam estes morais, religiosos, políticos ou econômicos". Marilena Chauí (2008), no entanto, adverte que o mais comum é tomar ideologia como um "conjunto sistemático e encadeado de ideias", quando na realidade trata-se de "um ideário histórico, social e político que oculta a realidade" (p. 8). A definição proposta por Zizek (1996) aglutina, de certa forma, as de Houaiss e Chauí: "doutrina, conjunto de ideias, crenças, conceitos e assim por diante, destinada a nos convencer de sua veracidade, mas, na verdade, servindo a algum inconfesso interesse particular do poder" (p.15, itálico meu).

Não raro, a ideologia se apresenta na forma de uma falsa consciência que conforma o discurso de um grupo a partir de interpretações particulares de fenômenos sociais. Muitos esquecem(os) que a todo processo (acusado de) ideológico, contrapõe-se outro contrário, que ainda que se apresente como neutro, é igualmente ideológico. É o que temos assistido no Brasil - e ao redor do mundo - em anos recentes.

Toda obra de arte está imbuída de ideologia, mais ou menos aparente, mais ou menos consciente. Mesmo a grande maioria que vai de encontro às exigências e facilidades da cultura de massas e do mercado editorial regido pelas regras do consumo, não é isenta ou neutra. No caso da LIJ, ocupam lugar de destaque livros produzidos a partir de personagens tornados famosos pela $\mathrm{TV}$, cinema, games e, mais recentemente, internet e canais de YouTube especialmente voltados ao 
público infantil. São abundantes também livros identificados com as demandas do politicamente correto, quase sempre produzidos especificamente para atender ao que ficou conhecido como temas transversais nos $\mathrm{PCN}^{20}$ (1997), e que aparece na $\mathrm{BNCC}^{16}$ (2017) como "temas contemporâneos que afetam a vida humana em escala local, regional e global" (p.19) contemplados em "habilidades dos componentes curriculares" (p.20).

A grande diferença que distingue uma obra literária de livros de apelo exclusivamente comercial e daqueles produzidos para atender a demandas escolares, é justamente sua qualidade estética. Na (infelizmente) pequena intersecção entre ética e estética, situam-se os livros politicamente comprometidos, que buscam profundidade e indeterminação na narrativa de temas sociais contemporâneos. Distante do corriqueiro politicamente correto, invariavelmente tratado como bandeira ideológica, a LIJ politicamente comprometida ${ }^{2 l}$ pode ser - de forma insuficiente sintetizada, como: textos que, sem descuidar de aspectos estéticos da experiência literária, buscam espelhar questões prementes da realidade social em que estão inscritos. O termo, praticamente ignorado no Brasil, engloba livros publicados, quase sempre, por pequenas editoras independentes, que não fazem parte de grandes conglomerados econômicos.

Chegando ao fim de uma discussão que insiste em escapar de fronteiras que lhe são impostas, é preciso, mais uma vez, voltar à mediação. Ao pensar sobre a construção de sentidos da leitura, no triângulo representado por texto / autor / leitor, Britto (2015) sugere a inclusão de instâncias como escola, família, amigos, que agregam múltiplas possibilidades ao processo de produção de sentidos. Como são múltiplos os sujeitos que participam desse processo - a criança pode apropriar-se e atribuir significados ao texto somente se o adulto lhe permitir que decifre, à sua maneira, um código que ainda não domina totalmente.

O principal desafio da mediação é garantir à criança oportunidade de ser sujeito no triálogo com o texto, possibilitando uma interação em que não apenas a autoridade do adulto determina

\footnotetext{
${ }^{20}$ Parâmetros Curriculares Nacionais / Base Nacional Comum Curricular. Duas décadas após aqueles definidos, pelos PCN (ética, meio ambiente, saúde, pluralidade cultural e orientação sexual), a BNCC abarca desde educação em direitos humanos e diversidade cultural até educação para o trânsito e valorização do idoso.

${ }^{21}$ No artigo "Para as barricadas? O que pode a literatura infantil politicamente engajada?" publicado no Caderno Emília 2 (dez/2018), o tradutor opta por politicamente engajado para o termo politically committed, no original em inglês, empregado por Beauvais (2015). Para além da preferência pessoal, considero a origem etimológica dos termos para adotar (desde 2016) politicamente comprometido, uma vez que: (i) comprometer-se, de compromitto (latim), tem como primeira definição dar em penhor moral; já (ii) engajar, com origem em engager (francês), é referido como contratar ou ser contratado para prestação de serviço (HOUAISS, 2012).
} 
significados. Na leitura mediada de um texto literário o adulto deve estar consciente de que sua recepção jamais será análoga à de uma criança, uma vez que é impossível suspender as experiências já vividas (NODELMAN, 2008). No entanto, para ler com uma criança, é preciso, de certa forma, voltar a ler como criança, empenhando-se na difícil tarefa de deixar de lado juízos, medos e preconceitos, adotando, na medida do possível, uma atitude de consentimento eufórico, em que "nossas crenças infantis, reativadas em certas condições (entre elas a situação de leitura), subentendem nossas crenças de adultos" (JOUVE, 2002, p. 117).

Como (in)conclusão de um tema abrangente, contemporâneo (mas não novo), carregado de polêmicas, ficam a defesa de uma ideia e um alerta. A defesa da necessidade de se produzir mais e melhores livros infantis politicamente comprometidos, tarefa que "provavelmente requer equilíbrio e sutileza literária notáveis" (COLOMER, 1994, p. 21). E o alerta de Perry Nodelman (1992), que em seu ensaio, honestamente denominado Somos todos censores, nos lembra que a censura, sob a máscara do cuidado, pode acometer a todos, sem distinção de convicções políticas, culturais e tantas outras.

\footnotetext{
Nós, os anticensores, tendemos a nos transformar em censores em relação a livros [infantis] que divergem de nossos próprios valores, teoricamente anticensórios (...). Isso talvez não seja surpreendente, mas é perigoso. Sugerir que temos o direito de encerrar discussões a respeito de qualquer assunto ou banir qualquer livro é meramente estabelecer que a censura, em determinadas circunstâncias, é apropriada; e se é apropriada em algumas, quem irá distinguir entre estas e outras quaisquer? (p.121).
}

\section{Referências}

APPIAH, Kwame Anthony. O código de honra: como ocorrem as revoluções morais. São Paulo: Companhia das Letras, 2012.

BELL hooks: American Scholar. In: RODRIGUEZ, Emily. Encyclopedia Britannica, 2019. Disponível em: https://www.britannica.com/biography/bell-hooks. Acesso em: 22 jul. 2020.

BETTELHEIM, Bruno. A psicanálise dos contos de fadas. São Paulo: Paz e Terra, 2002.

BEAUVAIS, Clémentine. The mighty child: time and power in children's literature. Amsterdam: John Benjamins Publishing Co, 2015. 
BRASIL. MINISTÉRIO DA EDUCAÇÃO. BNCC: Base Nacional Comum Curricular. Brasília, 2017. Disponível em: 〈http://basenacionalcomum.mec.gov.br/download-da-bncc〉. Acesso em: 10 nov. 2018.

BRITTO, Luiz Percival Leme. Ao revés do avesso: leitura e formação. São Paulo: Pulo do Gato, 2015.

CAMBRIDGE Dictionary. Politically correct. Disponível em: <https://dictionary.cambridge.org /us/dictionary/english/politically-correct>. Acesso em: 10 set. 2019.

CHAUÍ, Marilena. O que é ideologia? São Paulo: Brasiliense, 2008.

COLOMER, Teresa. A favor de las niñas: El sexismo en la literatura infantil. Cuadernos de Literatura Infantil y Juvenil, Barcelona, v. 57, n. 1, p.7-24, jan. 1994. Disponível em: <https://www.europeana.eu/portal/en/record/2022702/oai_prensahistorica_mcu_es_1008296.htm 1>. Acesso em: 5 set. 2019.

CONSTITUIÇÃO da República Federativa do Brasil de 1988: Assembleia Nacional Constituinte. Diário Oficial, Brasília, p. 1-32, 5 out. 1988. Disponível em: http://www.planalto.gov.br /ccivil_03/constituicao/constituicao.htm. Acesso em: 15 jul. 2020.

DOSSIÊ POLITICAMENTE CORRETO. São Paulo: Revista USP, 2017. Disponível em: <https://www.revistas.usp.br/revusp/issue/view/10545/1304>. Acesso em: 10 set. 2019.

GERALDI, João Wanderley. Leitura e mediação. In: BARBOSA, Juliana Bertucci; BARBOSA, Marinalva Vieira (Org.). Leitura e mediação: reflexões sobre a formação do professor. Campinas: Mercado de Letras, 2013. p. 25-48.

GOERGEN, Pedro. Educação e valores no mundo contemporâneo. 2005. Disponível em: <http://www.scielo.br/pdf/es/v26n92/v26n92a13.pdf>. Acesso em: 10 set. 2019.

GOMES, Wilson. Precisamos falar sobre o "lugar de fala”. Cult, São Paulo, 9 ago. 2019. Exclusivo do site. Disponível em: https://revistacult.uol.com.br/home/precisamos-falar-sobre-olugar-de-fala/. Acesso em: 15 jul. 2020.

HOOKS, bell. Ensinando a transgredir: a educação como prática da liberdade. São Paulo: WMF Martins Fontes, 2013.

HOUAISS, Antônio. Grande Dicionário Houaiss. 2012. Disponível em: https://houaiss.uol.com.br/pub/apps/www/v5-4/html/index.php\#0. Acesso em: 10 set. 2019.

JOUVE, Vincent. JOUVE, Vincent. A leitura. São Paulo: Unesp, 2002.

JOUVE, Vincent. A leitura como retorno a si: o interesse pedagógico das literaturas subjetivas. In: ROUXEL, Annie; LANGLADE, Gerard; REZENDE, Neide Luzia de (Org.). Leitura subjetiva $e$ ensino de literatura. São Paulo: Alameda, 2012. p. 53-65. 
NODELMAN, Perry. The Hidden Adult: defining Children's literature. Baltimore: The John Hopkins University Press, 2008.

NODELMAN, Perry. We are all censors. Canadian Children's Literature / Littérature Canadienne Pour La Jeunesse, Toronto, n. 68, p.121-133, set./dez. 1992. Disponível em: <http://ccllcj.ca/index.php/ccl-lcj/article/view/2799/2362>. Acesso em: 10 set. 2019.

PERRY, Ruth. Historically correct. The Women's Review of Books, Wellesley, v. 9, n. 5, p.15-16, fev. 1992. Disponível em: <http://www.jstor.org/stable/4021229>. Acesso em: 10 set. 2019.

PETIT, Michèle. Leituras: do espaço íntimo ao espaço público. São Paulo: Editora 34, 2013.

ROBLEDO, Beatriz Helena. El mediador de lectura: La formación del lector integral. Santiago, Chile: Ibby Chile, Fundación SM, 2017.

SILVEIRA, Rosa Hessel et al. A diferença na literatura infantil: narrativas e leituras. São Paulo: Moderna, 2012.

STEINER, George. Aqueles que queimam livros. Belo Horizonte: Âyiné, 2017.

SUDATTI, Ariani Bueno; SELIGMANN-SILVA, Márcio. Censura como meio de política dos afetos e bloqueio da argumentação. Revista USP, São Paulo, v. 119, p.59-72, out./dez. 2018. Disponível em: <https://jornal.usp.br/revistausp/revista-usp-119-dossie-4-censura-como-meio-depolitica-dos-afetos-e-bloqueio-da-argumentacao/>. Acesso em: 10 set. 2019.

WEIGEL, Moira. Um álibi para o autoritarismo. Serrote, São Paulo, n. 29, jul. 2018. Disponível em: <https://www.revistaserrote.com.br/2018/10/um-alibi-para-o-autoritarismo-por-moiraweigel/>. Acesso em: 10 set. 2019.

WILSON, John K. The Myth of Political Correctness: the conservative attack on higher education. Durham, London: Duke University Press, 1995.

XONGANI, Ana Paula. Vídeos (Peppa). Disponível em: https://www.youtube.com/user/ xonganiartecomtecido/videos

ZIZEK, Slavoj. O espectro da ideologia. In: ZIZEK, Slavoj (Org.). Um mapa da ideologia. Rio de Janeiro: Contraponto, 1996. p. 7-38.

Recebido em 31 de julho de 2020. Aceito em 23 de outubro de 2020. 